\title{
BMJ Open Quality Risk assessment of the hospital discharge process of high-risk patients with diabetes
}

\author{
Teresa A Pollack, ${ }^{1}$ Vidhya Illuri, ${ }^{1}$ Rebeca Khorzad, ${ }^{2}$ Grazia Aleppo, ${ }^{1}$ \\ Diana Johnson Oakes, ${ }^{1}$ Jane L Holl, ${ }^{2}$ Amisha Wallia ${ }^{1,2}$
}

To cite: Pollack TA, Illuri V, Khorzad R, et al. Risk assessment of the hospital discharge process of high-risk patients with diabetes.BMJ Open Quality 2018;7:e000224. doi:10.1136/ bmjoq-2017-000224

TAP and VI contributed equally.

Received 27 September 2017 Revised 6 March 2018 Accepted 8 April 2018
Check for updates

${ }^{1}$ Division of Endocrinology, Metabolism, and Molecular Medicine, Northwestern University Feinberg School of Medicine, Chicago, Illinois, USA ${ }^{2}$ Center for Health Care Studies, Institute for Public Health and Medicine, Northwestern University Feinberg School of Medicine, Chicago, Illinois, USA

Correspondence to

Dr Amisha Wallia;

a-wallia@fsm.northwestern.edu

\section{ABSTRACT}

Objectives Describe the application of a risk assessment to identify failures in the hospital discharge process of a high-risk patient group, liver transplant (LT) recipients with diabetes mellitus (DM) and/or hyperglycaemia who require high-risk medications.

Design A Failure Modes, Effects and Criticality Analysis (FMECA) of the hospital discharge process of LT recipients with DM and/or hyperglycaemia who required DM education and training before discharge was conducted using information from clinicians, patients and data extraction from the electronic health records (EHR). Failures and their causes were identified and the frequency and characteristics (harm, detectability) of each failure were assigned using a score of low/best (1) to high/worst (10); a Criticality Index ( $\mathrm{Cl}=$ Harm $\times$ Frequency) and a Risk Priority Number (RPN=Harm $\times$ Frequency $\times$ Detection) were also calculated.

Setting An academic, tertiary care centre in Chicago, Illinois.

Participants Healthcare providers $(\mathrm{N}=31)$ including physicians $(n=6)$, advanced practice providers $(n=12)$, nurses $(n=6)$, pharmacists $(n=4)$, staff $(n=3)$ and patients $(n=6)$ and caregivers $(n=3)$ participated in the FMECA; EHR data for LT recipients with DM or hyperglycaemia $(\mathrm{N}=100)$ were collected.

Results 0 78 identified failures, the most critical failures $(n=15 ; \mathrm{RPNs}=700,630,560 ; \mathrm{Cl}=70)$ were related to variability in delivery of diabetes education and training, care coordination and medication prescribing patterns of providers. Underlying causes included timing of patient education, lack of assessment of patients' knowledge and industry-level design failures of healthcare products (eg, EHR, insulin pen).

Conclusion Most identified critical failures are preventable and suggest the need for the design of interventions, informed by the failures identified by this FMECA, to mitigate safety risks and improve outcomes of high-risk patient populations.

\section{BACKGROUND}

Current gaps in transitions of care from the inpatient to outpatient setting have prompted both local and national initiatives to improve care processes more proactively. ${ }^{1}$ Acute care transitions, in particular, continue to result in communication breakdowns that have consistently been at the root of over $80 \%$ of reported events resulting in death or serious injury. ${ }^{2}$ After discharge from the hospital, $49 \%$ of patients experience a medical error and $19 \%-23 \%$ suffer an adverse event within 3 weeks of discharge, most commonly an adverse drug event. ${ }^{34}$

Insulin and oral antihyperglycaemic agents are identified as the second and fourth most common medications leading to hospitalisation due to adverse events. ${ }^{5}$ This study focuses on a particularly high-risk group of patients, post-liver transplant (LT) recipients with diabetes mellitus and or hyperglycaemia (heretofore referred to as 'DM'), who are discharged with a new DM medication(s). Indeed, up to $50 \%$ of LT recipients have new hyperglycaemia and $30 \%$ develop longterm DM. ${ }^{6}$ Most LT recipients have multiple healthcare providers and often times encounter transportation barriers to the urban care setting (downtown Chicago), making postdischarge chronic care planning especially complex. However, assuring safe postdischarge care of LT recipients with DM is critical because of the significant impact of unstable glucose levels on organ rejection and infection. ${ }^{7-9}$

While robust risk assessment approaches, such as a Failure Mode Effects and Criticality Analysis, have been used in surgery and emergency medicine, none have been applied to the complex discharge process for patients with new DM care needs. ${ }^{10} 11$ Although interventions, focused on the discharge process, have been evaluated, ${ }^{12-15}$ results are mixed and none have focused exclusively on risks in the hospital discharge process of patients with DM. A recent, systematic review of hospital-initiated transition programmes found that many of the tested interventions had little impact on rehospitalisation ${ }^{16}$ and, those that did, such as the Care Transitions Program and Project Red, ${ }^{15} 1718$ were complex and resource intensive. 
The objective of this study was to conduct a comprehensive, proactive risk assessment of the discharge process for LT recipients with DM at an academic, tertiary care hospital that cares for $>350$ transplant patients ( 100 LT) per year to identify opportunities to mitigate potential failures and prevent harm. ${ }^{19}$ Similar to many other high-risk industries (eg, nuclear energy, automotive), a Failure Modes Effects and Criticality Analysis (FMECA) was used,${ }^{20}$ with all relevant stakeholders (clinicians, staff, patients, caregivers) qualitatively describing the process with additional relevant electronic health record (EHR) data and direct observations to identify, characterise and rank identified failures. Underlying causes were classified and initial containment or permanent solutions were proposed for the most critical failures of the process.

\section{METHODS}

The study consisted of four phases (table 1).

The scope of the study began with the decision to discharge the patient by the primary team (transplant team) and ended when the patient was deemed ready to be discharged from the hospital.

Phase I consisted of the conduct of an FMECA, direct observations of the discharge process and patient tracers, ${ }^{21}{ }^{22}$ led by an industrial engineer (RK). First, potential failures, their underlying causes and the potential impact or harm of each identified failure were elicited during six FMECA sessions; one session with patients/ caregivers $(\mathrm{n}=9)$ and five sessions with clinicians/staff, including Certified DM Educators (CDE), physicians, advanced practice providers, nurses, pharmacists and clinic staff $(n=32)$. Next, direct observation $(n=10)$ of the discharge process from the perspective of all involved (eg, clinicians, staff) was conducted. Patient tracers $(n=6)$, a method developed by the Joint Commission, in which a patient's medical record is used to 'trace' the processes of care, were conducted..$^{212}$ For this study, the processes were traced from the perspective of an LT recipient with DM (and their caregiver) during the discharge process. The research team used the medical record to follow all the steps in the discharge process by interviewing patients and caregivers about what he/she experienced at each step. These data were used to create a process map.

For phase II, data were retrieved from the Enterprise Database Warehouse for LT recipients with DM $(n=100)$ to estimate hypoglycaemia and hyperglycaemia $(\leq 70 \mathrm{mg}$ / $\mathrm{dL}, \geq 200 \mathrm{mg} / \mathrm{dL}$ ) occurrences within 30 days post-transplantation, DM medication discrepancies in discharge instructions and 30-day outpatient telephone encounters to the specialty team (endocrinology team).

Phase III involved scoring the frequency (F), potential harm $(\mathrm{H})$ and current detection methods (D) of each failure using a high/best (1) to low/worst (10) scale, based on a scoring sheet, customised for DM (table 2).

A Criticality Index $(\mathrm{CI}=\mathrm{Harm} \times$ Frequency $)$ and a Risk Priority Number $\quad(\mathrm{RPN}=$ Harm $\times$ Frequency $\times$ Detection $)$ were then calculated for each failure. ${ }^{1123}$

In phase $I V$, failures were ranked by their highest index rank, a combination of both CI and RPN. Failures that involved processes for which the underlying cause was beyond the authority of the patient, clinician or healthcare institution were then identified as the responsibility of the healthcare industry. The highest ranked failures were reviewed with primary and specialty teams to ascertain clinical relevance and to gather initial containment or permanent solutions. Causes of the failures were classified using the Joint Commission Root Causes by Event Type (2004-2013). ${ }^{24}$

\begin{tabular}{|c|c|c|c|}
\hline Phase I & Phase II & Phase III & Phase IV \\
\hline Qualitative data & Quantitative data & Scoring & Ranking \\
\hline $\begin{array}{l}\text { Identify and list potential } \\
\text { failures (effects and } \\
\text { causes) }\end{array}$ & Medical record review $(n=100)$ & $\begin{array}{l}\text { Harm }(H) \\
\text { Frequency }(F) \\
\text { Detection }(D)\end{array}$ & $\begin{array}{l}\text { Top ranked Cls } \\
\text { Example: } \max \\
(\mathrm{H}=7) \times(\mathrm{F}=10)=70\end{array}$ \\
\hline Create process map & $\begin{array}{l}\text { Endocrinology or Certified Diabetes } \\
\text { Educator consultation prior to } \\
\text { discharge }\end{array}$ & $\begin{array}{l}\text { Scoring Scale } \\
\text { High/best: } 1 \\
\text { Low/worst: } 10\end{array}$ & $\begin{array}{l}\text { Assign root causes } \\
\text { Joint Commission } \\
\text { Classifications }\end{array}$ \\
\hline Direct observations & $\begin{array}{l}\text { Outpatient follow-up with } \\
\text { endocrinology clinic (phone calls and }\end{array}$ & $\begin{array}{l}\text { Criticality Index }(\mathrm{Cl}) \\
(\mathrm{H}) \times(\mathrm{F}) \text { scores }\end{array}$ & \\
\hline
\end{tabular}

DM, diabetes mellitus. 
Table 2 Diabetes mellitus risk scoring sheet

\section{Score Effect/consequence (harm)}

\begin{tabular}{|c|c|c|c|c|c|c|}
\hline 1 & None & $\begin{array}{l}\text { No reason to expect failure to } \\
\text { have any effect on safety, health, } \\
\text { environment or mission. }\end{array}$ & None & $1 / 10000$ & Almost certain & $\begin{array}{l}\text { Current control(s) almost } \\
\text { certain to detect failure mode. } \\
\text { Reliable controls are known } \\
\text { with similar processes. }\end{array}$ \\
\hline 3 & Low & $\begin{array}{l}\text { Minor disruption to discharge } \\
\text { process. Repair of failure may take } \\
30-60 \mathrm{~min} \text { to correct. } \\
\text { Outcome example: Blood glucose } \\
\text { is } 150-200 \mathrm{mg} / \mathrm{dL} \text {. } \\
\text { Process example: The provider } \\
\text { cannot find supplies immediately } \\
\text { because supplies are in different } \\
\text { locations. }\end{array}$ & Low & $1 / 2000$ & High & $\begin{array}{l}\text { High likelihood current } \\
\text { control(s) will detect failure } \\
\text { mode. } \\
\text { Example: Semiautomatic } \\
\text { mean of detection with } \\
\text { warning that does not prevent } \\
\text { the process from continuing } \\
\text { (eg, a pop-up window } \\
\text { reminder). }\end{array}$ \\
\hline 4 & $\begin{array}{l}\text { Low to } \\
\text { moderate }\end{array}$ & $\begin{array}{l}\text { Moderate disruption to discharge } \\
\text { process. Repair of failure takes } \\
2 \text { hours to correct. } \\
\text { Outcome example: Asymptomatic } \\
\text { hyperglycaemia (blood glucose } \\
\text { value is } 200-249 \mathrm{mg} / \mathrm{dL} \text { ). } \\
\text { Process example: The caregiver is } \\
\text { not present for diabetes education } \\
\text { session, discharge is delayed. }\end{array}$ & $\begin{array}{l}\text { Low to } \\
\text { moderate }\end{array}$ & $1 / 1000$ & $\begin{array}{l}\text { Moderately } \\
\text { high }\end{array}$ & $\begin{array}{l}\text { Moderately high likelihood } \\
\text { current control(s) will detect } \\
\text { failure mode. } \\
\text { Example: Semiautomatic } \\
\text { mean of detection (eg, an } \\
\text { alarm that does not prevent } \\
\text { the process from continuing). }\end{array}$ \\
\hline 6 & $\begin{array}{l}\text { Moderate } \\
\text { to high }\end{array}$ & $\begin{array}{l}\text { Moderate disruption to discharge } \\
\text { process. Discharge is delayed } \\
\text { 4-8hours. } \\
\text { Outcome example: Asymptomatic } \\
\text { hypoglycaemia (blood glucose } \\
\text { is }<70 \mathrm{mg} / \mathrm{dL} \text { ) or asymptomatic } \\
\text { hyperglycaemia (blood glucose } \\
\text { value is } 250-349 \mathrm{mg} / \mathrm{dL} \text { ). } \\
\text { Process example: New diabetes } \\
\text { or hyperglycaemia onset, patient } \\
\text { needs more time with diabetes } \\
\text { team to feel comfortable prior to } \\
\text { discharge. Discharge is delayed. }\end{array}$ & $\begin{array}{l}\text { Moderate to } \\
\text { high }\end{array}$ & $1 / 200$ & Low & $\begin{array}{l}\text { Low likelihood current } \\
\text { control(s) will detect failure } \\
\text { mode. } \\
\text { Example: Double human } \\
\text { inspection with a checklist or } \\
\text { standard aid, or triple human } \\
\text { inspection without checklist } \\
\text { or standard aid. }\end{array}$ \\
\hline
\end{tabular}

\section{Frequency of failure}

(frequency)/patients

Safeguard detectability (detection) 
Table 2 Continued

\section{Score Effect/consequence (harm)}

Frequency of failure (frequency)/patients

High 1/100 Very low process (1 day). Outcome example: Symptomatic hypoglycaemia (blood glucose is $<70 \mathrm{mg} / \mathrm{dL}$ ) or symptomatic hyperglycaemia (blood glucose value is $250-349 \mathrm{mg} / \mathrm{dL}$ ).

Process example: Patient deemed ready for discharge and diabetes team consulted. Patient needs more time with diabetes team before leaving the hospital. Discharge is delayed to the next day.

\section{8}

Very high Patient suffers non-permanent damage or needs acute intervention.

Outcome example: Asymptomatic hypoglycaemia (blood glucose is $<40 \mathrm{mg} / \mathrm{dL}$ ) or asymptomatic hyperglycaemia (blood glucose is $>350 \mathrm{mg} / \mathrm{dL}$ ). Rejection and infection risk increased.

\begin{tabular}{|c|c|c|c|c|c|c|}
\hline 9 & Hazard & $\begin{array}{l}\text { Potential safety, health or } \\
\text { environmental issue. } \\
\text { Outcome example: Symptomatic } \\
\text { hypoglycaemia (blood glucose } \\
\text { is }<40 \mathrm{mg} / \mathrm{dL} \text { ) or symptomatic } \\
\text { hyperglycaemia (blood glucose } \\
\text { is }>350 \mathrm{mg} / \mathrm{dL} \text { ). Heart attack } \\
\text { or seizure or retransplant is } \\
\text { associated with hypoglycaemia or } \\
\text { hyperglycaemia. }\end{array}$ & Hazard & $1 / 20$ & Very remote & $\begin{array}{l}\text { Very remote likelihood current } \\
\text { control(s) will detect failure } \\
\text { mode. }\end{array}$ \\
\hline 10 & Hazard & $\begin{array}{l}\text { Potential safety, health or } \\
\text { environmental issue. } \\
\text { Outcome example: Blood glucose } \\
\text { is }<40 \mathrm{mg} / \mathrm{dL} \text {. Patient dies. }\end{array}$ & Hazard & $1 / 10+$ & $\begin{array}{l}\text { Almost } \\
\text { impossible }\end{array}$ & $\begin{array}{l}\text { No known control(s) available } \\
\text { to detect failure mode. }\end{array}$ \\
\hline
\end{tabular}

DM, diabetes mellitus.

\section{RESULTS}

Seventy-eight (78) total failures in the discharge process of high-risk patients with DM were identified. Of the 78 failures, $50(74 \%)$ had an estimated frequency of 1 in 100 patients (frequency score $\geq 7$ ) and $27(35 \%)$ had evidence of patient harm (harm score $\geq 7$ ) (eg, symptomatic hypoglycaemia or hyperglycaemia). Failures with harm scores $<7$ were not further characterised. No failures with a harm score of 9 or 10 (permanent harm or death) were identified. The underlying causes of failures were variability and suboptimal performance in three specific areas: (1) delivery of diabetes education and training (comprehension/self-care assessment); (2) care coordination; and (3) lack of standardised prescribing by providers. Table 3 shows the top ranked failures in each area, and potential containment and permanent solutions.

\section{Failures in delivery of DM education and training}

Lack of availability of training supplies, specifically the insurance covered DM supplies for self-care at home, was identified as the highest ranked failure given the inconsistent availability of DM supplies. Other failures were lack of systematic and readily available predischarge evaluation of patients' self-care competencies and variability in length and intensity of predischarge education, due to clinician time constraints and also occurred whether a CDE was available or not (eg, weekdays or weekends, evenings).

\section{Failures in care coordination}

Overall, failures in coordination of postdischarge care needs by the transplant team were highly ranked and included inconvenient and/or uncoordinated follow-up 


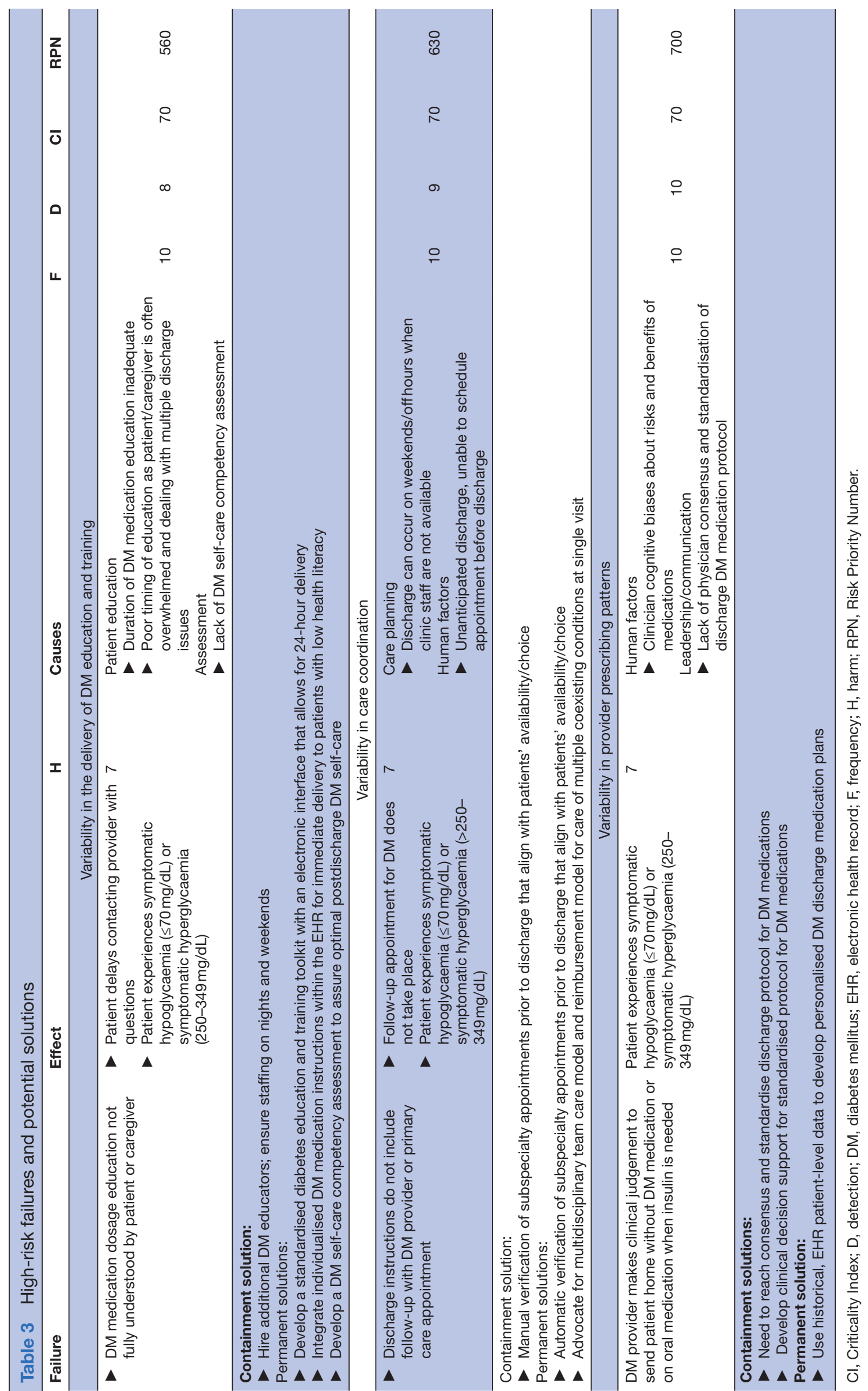


appointments; failure to address specific DM discharge needs and failure to consider level of glycaemic control at discharge (eg, initiating a post-transplant discharge process while patient still has elevated glucose level); and conflicting EHR-generated discharge instructions, particularly medications (eg, different DM medication doses in different sections of discharge instructions). Underlying causes of these failures included variation in staffing level; particularly outside of regular work week hours, and lack of integration and consideration of specialty care team discharge recommendations by the transplant team.

\section{Failures in provider prescribing patterns}

Variation in discharge medication prescribing by clinicians had the highest RPN and CI. Both observational and EHR data revealed clinician preferences for prescribing oral antihyperglycaemics rather than insulin. This may be due, in part, to clinicians' awareness of the failures in DM education and skills training and belief that more comprehensive DM education and training prior to discharge is essential for patients being discharged on insulin, or perhaps provider perception that patient/ family may be unable to safely deliver a high-risk medication such as insulin.

\section{Product design and patient/caregiver-reported failures}

Surprisingly, several major failures were identified with underlying causes beyond the control of patients, clinicians or the healthcare institution, but related to fundamental aspects of product design, as summarised in table 4 . These high-risk failures are specifically the responsibility of the Food and Drug Administration (FDA), pharmaceutical industry and/or the EHR companies.

Patients and caregivers noted that external similarities (eg, colours, shape) of DM insulin pens could lead to self-administration of the wrong type of insulin (eg, long acting instead of short acting). Patients and caregivers noted other significant failures including incomplete, inaccurate or conflicting medications and medication dosing in discharge instructions (both EHR generated and handwritten), and lack/variability of verification of insurance coverage of prescribed medications and supplies. The lack of EHR capability to automatically reconcile inpatient medications with discharge medications in a user-friendly and timely manner is a design failure and the underlying cause of incomplete, inaccurate or conflicting medication discharge instructions.

Patients/caregivers noted the high frequency of change in insurance coverage of supplies (eg, glucose meter, strips) and medications (eg, type of insulin, oral antihyperglycaemics). Providers confirmed that this failure leads to suboptimal outcomes, including delays in obtaining medications/supplies or needing to request changes in non-covered supplies, which can be difficult outside of regular workweek hours because of difficulties in availability of pharmacists and/or educators.

\section{Proposed solutions}

All failures were further categorised as either institutional or industry related. For failures identified by patients and caregivers during the qualitative sessions, they were asked, at the end of the session, to offer potential "patient-centered' solutions to address each of their identified failures (table 5).

Potential solutions for institutional-related failures were developed by having the principal investigator (AW) present the findings at several institutional Quality Committee Meetings and at several stakeholder (CDE, physicians, advanced practice providers, nurses, pharmacists and clinic staff) meetings, facilitated by the principal investigator (AW) and the industrial engineer (RK). Both groups were asked to propose solutions and to then reach consensus. Potential containment solutions were additionally generated by the research team in conjunction with the clinical teams. Solutions for industry-related failures (eg, similarity of insulin injector pen colours) were generated by the patient safety expert (JLH) and the industrial engineer (RK) after reviewing FDA device approval processes.

With regard to DM education and training, recommended potential proposed solutions include standardisation of education for DM medications and creation of a training toolkit with web-based videos, development of an evidence-based DM medication prescribing protocol, customised for transplant patients, as well as discharge medication reconciliation, with EHR clinical decision support. Routine data audits (eg, glucose discharge data) could be used to provide continuous feedback about medication prescribing decisions and patient outcomes postdischarge. Additional recommended solutions include integration of a primary team representative (eg, transplant pharmacists or nurses) into the specialty (endocrinology) service discharge and DM education processes.

More general patient and caregiver recommended solutions include use of comprehensive discharge 'packets', with a medication reconciliation form including pictures of each medication, a description, in lay terms, of each medication's purpose, and clear dosing and administration instructions of each medication; use of a method (eg, colour coding) that links each medication to its disease process or care team (eg, all instructions for DM care on pink-coloured paper); a document with photographs of key clinicians involved in the patient's care, their name, role and routine and off hours contact information.

\section{DISCUSSION}

The FMECA is a robust method, adapted from industrial and quality engineering, for identifying multiple failures in the discharge process of high-risk, hospitalised patients, such as LT recipients with DM. Indeed, many of the identified failures are highly applicable to this patient population who will need complicated self-care, immediately after discharge. The three key areas of patient safety risks 
Table 4 High-risk industry failures and potential solutions

\begin{tabular}{|c|c|c|c|c|c|c|c|}
\hline Failure & Effect & $\mathbf{H}$ & Causes & $\mathbf{F}$ & D & Cl & RPN \\
\hline \multicolumn{8}{|l|}{ High-risk industry level } \\
\hline $\begin{array}{l}\text { Diabetes education does } \\
\text { not highlight similarity in } \\
\text { insulin pens (eg, colour of } \\
\text { rapid-acting vs long-acting } \\
\text { pen); patient does not } \\
\text { remember or realise the } \\
\text { difference }\end{array}$ & $\begin{array}{l}\text { Wrong insulin pen used; } \\
\text { incorrect dose; incorrect type of } \\
\text { insulin } \\
\text { Patient experiences symptomatic } \\
\text { hypoglycaemia ( } \leq 70 \mathrm{mg} / \mathrm{dL}) \text { or } \\
\text { symptomatic hyperglycaemia } \\
(250-349 \mathrm{mg} / \mathrm{dL})\end{array}$ & 7 & $\begin{array}{l}\text { Medication use } \\
\text { Similarity of insulin pens } \\
\text { Patient education } \\
\text { Variation in training by } \\
\text { endocrinology/diabetes } \\
\text { providers/educators in } \\
\text { addressing the similarities of pens } \\
\text { Not all pens are available for } \\
\text { inpatient teaching; potential } \\
\text { failure not detected }\end{array}$ & 10 & 9 & 70 & 630 \\
\hline
\end{tabular}

Containment solution:

Instructions highlighting the design similarities of insulin pens during education

Permanent solution:

- Add provision to FDA approval mechanism (release to market approval) for improved differentiation of pens (type/design)

$\rightarrow$ Contradicting DM medication instructions in different sections of discharge instructions
- DM postdischarge medication error leading to symptomatic hypoglycaemia $(\leq 70 \mathrm{mg} / \mathrm{dL})$ or symptomatic hyperglycaemia (250-349 mg/dL)
7 Healthcare information technology, Leadership

- Lack of integration of discharge instructions from multiple care teams, specifically for high-risk medications

- Automated discharge medication list does not provide accurate 10870 discharge instructions

Human factors and communication

- Transcription error when discharge instructions are manually integrated

- Complexity of instructions care delivery by a CDE; however, it remains time intensive and with the high patient demand the resources are limited. In addition, 24-hour access and standardisation of education, regardless of provider function, and outside the healthcare setting, were solutions requested by patients and their caregivers. Specific patient comprehension assessment tools or tests to assess deficiencies in comprehension, beyond current, ad hoc, single assessments typically conducted by a nurse or to discharge, are potential high-value, impactful and permanent solutions. This is currently reflected in the 
Table 5 Patient and caregiver recommended solutions

Failures Recommended solutions

Pretransplant

Diagnosis of DM not expected

'I was not told this was a possibility before my transplant'
- During the pretransplant education sessions, explain to patients that developing high blood sugar and needing medications can happen after transplantation.

\section{Post-transplant discharge}

- Many different providers giving different sets of instructions at discharge

'We can't tell who is who'

'Too much information that does not register at that time'

'Dietician did not talk to me about diabetic diet'

- Have the clinical teams work together to give one set of instructions (transplant, endocrine, nutrition)

- Colour code the discharge instructions by clinical service

- Provide a single list of emergency contact for each clinical service (transplant, endocrine) and telephone number

- Create a brochure that includes a picture, name, clinical service and role of all providers:

- Physician name

- Attending physician

- Endocrinology (diabetes)

- Medication identification and training 'We overshot ourselves'

'No one took this pen and told us how to uncap it' 'I created my own list [meds] since they were all not on it...'

'I was on syringes and had to switch to pens but was not trained on pens'

- Insufficient or missing supplies

'I ran out of the supplies right away'
- Provide patients with a chart with a picture of each medication that they will be taking, as part of the discharge instructions.

- Provide accurate training materials for each type of medication type and each delivery system
Insufficient explanation about importance of each medication, how it works and how long it works

'I missed a dose and was so worried about it'

\section{After discharge}

Problems with making appointments after discharge

'If they can schedule the first appointment for us... we haven't even met the doctor...'

- Communication after discharge 'It was helpful to have one point contact throughout our care'
Make follow-up appointments before patient is discharged from the hospital
- Use patient-specific supplies for education and training prior to discharge

- Identify high-risk individuals who may require medication/supplies immediately

- Provide a uniform discharge 'packet' with complete diabetes and medication information, including pictures of each medication educator are lacking in the hospital discharge process. This study strongly supports the need to develop technology-enabled and more systematic assessment tools, incorporating proven methods, such as the 'teach back' method, where the patient explains in his/her own words and/or demonstrates a taught technique, skill or task. ${ }^{26}$ The ability to offer standardised, comprehensive education and training outside of regular workweek hours is strongly supported by the findings.

Variation in discharge recommendations, particularly DM medications, prescribed by the endocrinology team, was also a highly ranked failure, suggesting the need for clinicians and healthcare institutions to better examine and understand the underlying causes of variability in clinical care decisions among providers. Consensus-derived DM discharge prescribing guidelines and subsequent institution-level auditing and feedback are critically needed to optimise medication prescribing, reduce medication errors, and reduction of harm from hyperglycaemia or hypoglycaemia. Validated institution-specific guidelines could then be embedded within an EHR decision support tool. 
Perhaps the most interesting findings, given the numerous recommended solutions from patients, caregivers and clinicians, reveal the need for user-centred design of the discharge process at several levels. This study highlighted failures beyond the reach of the institution, such as automated discharge instructions generated by the EHR, thought to be convenient and time saving, yet, in the case of multiple, complex medications, leading to inaccurate/incomplete instructions causing patient confusion and medication errors at home. However, application of user-centred design principles to EHR software to support coordination of medication prescribing, education and training, reconciliation, and discharge instructions of high-risk medications, while a potential permanent solution, is beyond the capability or control of any single healthcare institution or clinicians, requiring substantial investment and fundamental informatics system redesign by EHR vendors. Indeed, EHR vendor adherence to usability certification requirements and testing standards are generally low $^{27}$ and 'gag' orders make it difficult for investigators or safety experts to directly investigate EHR-related failures.

Several critical product design failures were also uncovered. Pharmaceutical companies do not currently have any initiatives to clearly differentiate the external appearance of medications, such as insulin pens, to decrease medication errors. Currently, adverse, postdischarge events are estimated to cost \$12-\$44 billion annually in the $\mathrm{USA}^{28}$ and hospitals are now penalised for readmissions with reductions in reimbursement but also with payments available for high-quality discharge practices. ${ }^{129}$

This study has several limitations. First, generalisability may be limited because the study was conducted at a single institution within an academic hospital, in a highly subspecialised patient population, with a specialised diabetes service. However, the results appear to reveal many common failures, applicable to many patients on many hospital services, and recommended solutions are likely to be applicable to any inpatient with a chronic disease(s). Second, the FMECA methodology itself has some known limitations. Among other high-risk industries, the method is considered to be a moderate-level safety assessment method. ${ }^{30}{ }^{31}$ While it is recognised as a good way to map a process, the subjective nature of asking participants to estimate numerical scores for frequency, potential harm and detection of each failure denotes an unwarranted impression of objectivity and precision. ${ }^{32}$ However, for this study, we leveraged patient-level EHR data to improve the precision, accuracy and comprehensiveness of scoring identified failures.

A strength of this study is the inclusion of patients and caregivers in the FMECA. We are unaware of any prior published study that includes results provided by patients and caregivers, although the WHO endorses patient/ caregiver involvement ${ }^{33}$ 'as full partners in reform initiatives, and learning can be used to inform systemic quality and safety improvements.' Patient satisfaction is a key metric in healthcare and is related to better health outcomes ${ }^{34}$ and is now used for reimbursement by Medicare/Medicaid, ${ }^{35}$ and many institutions give patients the opportunity to provide feedback in the form of surveys or ability to share experience, ${ }^{36}$ but none have actually integrated their feedback into this type of risk assessment method.

A proactive, comprehensive risk assessment is, first, critical steps for healthcare institutions to better understand patient risks in complex care processes, such as patient discharge. However, accountability for improvement in the discharge process may need to extend well beyond the patient, clinician or institution. Other institutions can use the methods outlined here to evaluate risks of their current discharge process. Eventually potential cross-institutional comparisons could identify more generalisable failures and potential solutions to better address the complexities of the transition of care for high-risk patients. Further root cause evaluation with subsequent development and testing of containment and permanent solutions needs to occur at the patient, clinician, institutional and product design levels.

Acknowledgements We thank Mark Molitch, MD, and Daniela Ladner, MD, MPH, for their support and advice, and Kathleen Schmidt, APN, FNP-BC, Erica Tayaban, APN, FNP-BC, and Maggie Steingraber-Pharr, APN, FNP-BC, for their valuable input and participation as members of the Glucose Management Service and the Northwestern Division of Endocrinology, Metabolism, and Molecular Medicine Attending Physicians and Fellows who also took care of these patients at discharge.

Contributors AW, TAP, RK, VI and JLH planned the study. AW, TAP, VI, GA and DJO helped recruit study participants (patients and clinicians). AW, TAP, RK, VI and JLH gathered and analysed the data. RK and JLH provided guidance as subject matter experts in the methodologies. AW, TAP, RK, VI, JLH, GA and DJO all participated in the interpretation of the study results and preparation of the manuscript.

Funding American Diabetes Association Junior Faculty Award (1-13-JF-54).

Competing interests AW currently receives research salary/grant support from Merck and El Lilly and is a consultant for Glytec and completes adjudication for Lexicon Pharmaceuticals. GA currently receives research salary/grant support from Bristol-Myers Squibb, AstraZeneca and Helmsley Charitable Trust and is a consultant for Novo Nordisk, Dexcom and Boehringer Ingelheim.

Ethics approval NU Institutional Review Board Office.

Provenance and peer review Not commissioned; externally peer reviewed.

Open Access This is an Open Access article distributed in accordance with the Creative Commons Attribution Non Commercial (CC BY-NC 4.0) license, which permits others to distribute, remix, adapt, build upon this work non-commercially, and license their derivative works on different terms, provided the original work is properly cited and the use is non-commercial. See: http://creativecommons.org/ licenses/by-nc/4.0/

(c) Published by the BMJ Publishing Group Limited. For permission to use (where not already granted under a licence) please go to http://www.bmj.com/company/ products-services/rights-and-licensing/

\section{REFERENCES}

1. Kim CS, Flanders SA. In the Clinic. Transitions of care. Ann Intern Med 2013;158:ITC3.

2. Ong MS, Coiera E. A systematic review of failures in handoff communication during intrahospital transfers. Jt Comm J Qual Patient Saf 2011;37:274-AP8.

3. Kripalani S, Jackson AT, Schnipper JL, et al. Promoting effective transitions of care at hospital discharge: a review of key issues for hospitalists. J Hosp Med 2007;2:314-23.

4. Forster AJ, Murff HJ, Peterson JF, et al. The incidence and severity of adverse events affecting patients after discharge from the hospital. Ann Intern Med 2003;138:161-7. 
5. Budnitz DS, Lovegrove MC, Shehab N, et al. Emergency hospitalizations for adverse drug events in older Americans. $N$ Engl J Med 2011;365:2002-12.

6. Galindo RJ, Wallia A. Hyperglycemia and diabetes mellitus following organ transplantation. Curr Diab Rep 2016;16:14.

7. Wallia A, Parikh ND, Molitch ME, et al. Posttransplant hyperglycemia is associated with increased risk of liver allograft rejection. Transplantation 2010;89:222-6.

8. Wallia A, Parikh ND, O'Shea-Mahler E, et al. Glycemic control by a glucose management service and infection rates after liver transplantation. Endocr Pract 2011;17:546-51.

9. Wallia A, Schmidt K, Oakes DJ, et al. Glycemic control reduces infections in post-liver transplant patients: results of a prospective, randomized study. J Clin Endocrinol Metab 2017;102:451-9.

10. Nagpal K, Vats A, Ahmed K, et al. A systematic quantitative assessment of risks associated with poor communication in surgical care. Arch Surg 2010;145:582-8.

11. Prabhakaran S, Khorzad R, Brown A, et al. Academic-Community hospital comparison of vulnerabilities in door-to-needle process for acute ischemic stroke. Circ Cardiovasc Qual Outcomes 2015;8(6 Suppl 3):S148-54

12. Anthony D, Chetty VK, Kartha A. et alRe-engineering the Hospita Discharge: An Example of a Multifaceted Process Evaluation. In: Henriksen K, Battles JB, Marks ES, Lewin DI, . eds. Advances in Patient Safety: From Research to Implementation Volume 2: Concepts and Methodology. Rockville (MD: Advances in Patient Safety, 2005.

13. Takeda A, Taylor SJC, Taylor RS, et al. Clinical service organisation for heart failure. Cochrane Database Syst Rev 2012;60:CD002752.

14. Albert NM, Barnason S, Deswal A, et al. Transitions of care in heart failure: a scientific statement from the American Heart Association. Circ Heart Fail 2015;8:384-409.

15. Jack BW, Chetty VK, Anthony D, et al. A reengineered hospital discharge program to decrease rehospitalization: a randomized trial. Ann Intern Med 2009;150:178-87.

16. Rennke S, Nguyen OK, Shoeb MH, et al. Hospital-initiated transitional care interventions as a patient safety strategy: a systematic review. Ann Intern Med 2013;158(5 Pt 2):433-40.

17. Coleman EA, Parry C, Chalmers S, et al. The care transitions intervention: results of a randomized controlled trial. Arch Intern Med 2006;166:1822-8.

18. Berkowitz RE, Fang Z, Helfand BK, et al. Project ReEngineered Discharge (RED) lowers hospital readmissions of patients discharged from a skilled nursing facility. J Am Med Dir Assoc 2013;14:736-40.

19. Institute for Healthcare Improvement. The breakthrough series: IHI's Collaborative model for achieving breakthrough improvement. Massachusetts: Institute for Healthcare Improvement, 2003.

20. Stamatis DH. Failure mode and effect analysis: FMEA from theory to execution. 455. 2nd Edn. Milwaukee, Wisconsin: ASQ Quality Press, 2003
21. The Joint Commission Survey. Maximizing tracer activities: a dialogue with surveyors. Oakbrook Terrace, IL, 2012.

22. Halvorsen M, Pejakovich P, Loria G. Tracer methodology: an evolution. Marblehead, MA, 2008.

23. McElroy LM, Khorzad R, Nannicelli AP, et al. Failure mode and effects analysis: a comparison of two common risk prioritisation methods. BMJ Qual Saf 2016;25.

24. Joint Commission Sentinel Event Data. Root Causes by Event Type: Joint Commission; 2004-2015. 2018. http://www. jointcommission.org/assets/1/18/Root_Causes_Event_Type_20043Q 2015.pdf

25. Greenwald JL, Jack BW. Preventing the preventable: reducing rehospitalizations through coordinated, patient-centered discharge processes. Prof Case Manag 2009;14:135-40.

26. Schillinger D, Piette J, Grumbach K, et al. Closing the loop: physician communication with diabetic patients who have low health literacy. Arch Intern Med 2003;163:83-90.

27. Ratwani RM, Benda NC, Hettinger AZ, et al. Electronic health record vendor adherence to usability certification requirements and testing standards. JAMA 2015;314:1070-1.

28. Hansen LO, Young RS, Hinami K, et al. Interventions to reduce 30-day rehospitalization: a systematic review. Ann Intern Med 2011;155:520-8.

29. Hassan Sadek N, Sadek AR, Tahir A, et al. Evaluating tools to support a new practical classification of diabetes: excellent control may represent misdiagnosis and omission from disease registers is associated with worse control. Int J Clin Pract 2012;66:874-82.

30. Hudson P. Applying the lessons of high risk industries to health care. Qual Saf Health Care 2003;12(Suppl 1):7-12

31. Lyons M, Adams S, Woloshynowych M, et al. Human reliability analysis in healthcare: A review of techniques. International Journal of Risk and Safety in Medicine 2004;16:223-37.

32. Dean Franklin B, Shebl NA, Barber N. Failure mode and effects analysis: too little for too much? BMJ Qual Saf 2012;21:607-11.

33. World Health Organization. Patients for patient safety- statement of case. 2017. http://www.who.int/patientsafety/patients_for_patient/ statement/en/

34. Boulding W, Glickman SW, Manary MP, et al. Relationship between patient satisfaction with inpatient care and hospital readmission within 30 days. Am J Manag Care 2011;17:41-8.

35. The Commonwealth Fund.. Improving Health Care Delivery: the "Learning Collaborative" approach. 2005. http://www. commonwealthfund.org/Content/Innovations/Tools/2005/Jun/ Improving-Health-Care-Delivery-The-Learning-CollaborativeApproach.aspx

36. Cleary PD. The increasing importance of patient surveys. Now that sound methods exist, patient surveys can facilitate improvement. BMJ 1999;319:720-1. 